\title{
The biogas production from mesophilic anaerobic digestion of vinasse
}

\author{
Belhadj S. ${ }^{1}$, Karouach F. ${ }^{1}$, El Bari H. ${ }^{1}$, Joute Y. ${ }^{1}$ \\ ${ }^{I}$ Biogas Equipe, Biotechnology Laboratory Environment and Quality (LABEQ) - Faculty of Sciences - Ibn \\ Tofail University - Kenitra - Morocco
}

\begin{abstract}
Vinasse is a mixture of water, organic and inorganic compounds. This liquid residue after distillation of the alcohol, present a surcharge for the industry distillers, views its high pollution load, which can contaminate water and soil, causing a big environmental problem. The treatment by anaerobic digestion can be used to reduce the pollution of this type of waste, while producing biogas, which is a renewable energy. The objective of this study is to determination of the potential of biogas from the anaerobic digestion of vinasse in Morocco, and keeping the stability of physic-chemical parameters in the environment. The experiment test were realized in laboratory scale using the mesophilic digester at $35^{\circ} \mathrm{C}$ and with $0.5 \mathrm{~L}$ capacity, and using as raw material the vinasse from the process of the production of ethyl alcohol. The results obtained in this study indicate that the anaerobic digestion under mesophilic conditions, presents a reliable solution for production of biogas by treatment of this type of waste, this is proved by the increase in the volume of biogas collected which could reach $370 \mathrm{~mL}$ of biogas for a load of $0.5 \mathrm{~g} \mathrm{VS}$ added, with a yield coefficient in biogas $0.7 \mathrm{~L} / \mathrm{g} \mathrm{VS}$.
\end{abstract}

Keywords: Anaerobic Digestion-Biogas - Digester-mesophilic-pH-Vinasse - Volatile solids.

\section{INTRODUCTION}

Currently, there is a great improvement in the renewable energy sector to mitigate a high consumption of fossil fuels. In this sense, the process of anaerobic digestion of organic wastes is a technology that can reduce or eliminate their content of organic matter, mainly turned into methane, which has a high calorific value: 9.96 $\mathrm{kW} \cdot \mathrm{h} / \mathrm{m} 3[1]$, its combustion does not contribute to the greenhouse effect because of its renewable sources.

The Distillery produce large quantities of waste, such as the vinasse, that is characterized by low $\mathrm{pH}$ [2]; the production of one liter of ethanol generate on average between 10-15 liters of vinasse [3]. Vinasse is the waste water from the production of ethyl alcohol by fermentation, it is highly acidic and contains abundant organic matter (often more than 70-80g COD / 1). This type of waste can be effectively purified by anaerobic digestion. The process produces low sludge, thereby facilitating its removal. Moreover, vinasse is chemically very complex [4].

In general, slops are rich in minerals such as potassium, calcium, and sulfur, and have a high content of organic matter, characterized by high levels of BOD and COD [5].

Despite its strengths, it should not be forgotten that the vinasse is a important source of pollution when discharged without precautions in the river or that she penetrates into the groundwater.

The major problem of the filing of the vinasse is the possibility of its draining into rivers and lakes, especially during rainy days [6].

However, some studies have indicated that the placing of vinasse in landfill can lead to groundwater contamination, and can also produce disagreeable odor emissions due to the putrefaction of organic matter [5].

Due to the problems discussed above, the anaerobic treatment is more adequate for this type of waste compared to other treatment alternatives. In the literature, good results for the COD reduction have been reported (up 95.9\%) [5]. Of the theoretical data have been used to estimate the potential of biogas from anaerobic digestion of vinasse, which is to $14.6 \mathrm{~m}^{3}$ per $1 \mathrm{~m}^{3}$ of vinasse [6].

In Morocco, the country has an ethanol distillery by fermentation of the beet molasses and cane sugar. His products placed on the market are used in various sectors, namely chemical and para-chemical, food processing, perfumes and cosmetics, pharmaceutical and gas needs. Production of vinasse in this distillery is $18 \mathrm{~m}^{3} / \mathrm{h}$

The objective of this experiment is to evaluate the feasibility of anaerobic digestion of vinasse while producing biogas. The loads added of the organic matter for feeding the digester is measured by calculating and following up the value of volatile solids in the process, and the production of biogas, with an increase in the volume of organic matter added between loads to avoid the problem of overloading of milieu. 


\section{MATERIALS AND METHODS}

\section{II.1 Equipment:}

The digester used in semi-continuous mode, has a diameter of $8 \mathrm{~cm}$, with an internal height of $15 \mathrm{~cm}$ and a capacity of $0.5 \mathrm{~L}$. The substrate is maintained homogeneous within the digester, by a magnetic stirrer. The digester is immersed in a bath of water to a mesophilic temperature $\left(35^{\circ} \mathrm{C} \pm 2{ }^{\circ} \mathrm{C}\right)$. The biogas produced is collected in a Mariotte flask. The volume variance of biogas produced over time is determined by the volume of water displaced.

\section{II.2 Inoculum:}

The digester was inoculated with biomass from an industrial anaerobic reactor, used to treat wastewater from distillery. This biomass contains a methanogenic flora capable of degrading the effluent; these microorganisms can accelerate the starting of the anaerobic digestion. The chemical composition of the inoculum is shown in TABLE 1.

\begin{tabular}{ll} 
TABLE 1. Chemical composition of the biomass of the inoculum & \\
\hline pH & 6.56 \\
Moisture (\%) & 97.68 \\
Totals Solids TS $(\%)$ & 2.32 \\
Totals Solids TS $(\mathrm{g} / \mathrm{L})$ & 23.208 \\
Minerals Solids MS (g/L) & 12.934 \\
Volatils Solids VS $(\mathrm{g} / \mathrm{L})$ & 10.274 \\
\hline
\end{tabular}

\section{II.3 Vinasse:}

Vinasse used in this experiment to study the anaerobic digestion, is produced from a line of production of ethyl alcohol from a distillery unit (Kenitra, Morocco). The physico-chemical characteristics of the vinasse are shown in TABLE 2.

\begin{tabular}{ll} 
TABLE 2. Physico-chemical parameters of vinasse & \\
\hline pH & 4.51 \\
Moisture (\%) & 95.65 \\
Totales Solides TS (\%) & 4.35 \\
Volatiles Solides VS (\% ST) & 58.56 \\
Minerales Solides MS (\% ST) & 41.44 \\
Totales Solides TS (g/L) & 43.473 \\
Minerales Solides MS (g/L) & 18.014 \\
Volatiles Solides VS (g/L) & 25.459 \\
\hline
\end{tabular}

\section{II.4 Experimental Procedure:}

The experiment is performed in batch mode. At first the digester is filled with a volume of inoculum from an industrial anaerobic reactor, used to treat wastewater distilling ( $70 \%$ of digester volume), to ensure a good startup of the process. Then feed in a way, more or less, to a daily charge of $0.25 \mathrm{~g} \mathrm{SV}$ vinasse, and then move to a higher load of $0.5 \mathrm{~g} \mathrm{SV}$ when the biogas recovered ceased to be liberate in appreciable quantities. This scalability must be adapted to the specific activity of microorganisms, as a risk of organic overload can cause an imbalance or malfunction of the process, and therefore the stopping of anaerobic digestion. Biogas production has been completed, depending on the rate of biochemical reactions and biodegradability of the microorganisms during anaerobic digestion. The duration of this experiment was 16 days.

\section{II.5 Chemical Analysis:}

The following parameters were analyzed in the laboratory: $\mathrm{pH}$, humidity, total solids, mineral solids, volatile solids. These analyzes were performed using" Standard Methods for the Examination of Water and Wastewater" [7].

\section{RESULTS AND DISCUSSION}

The experimental results were used to evaluate the behavior of the anaerobic digestion of vinasse. Stability, biodegradability and biogas yield are determined by tracking parameters of the experiment. 


\section{III.1 Stability of the digester:}

Several experiments have shown that they exist a number of factors that influence the process of anaerobic digestion, for this it is necessary to ensure that the experiment is performed under stable conditions, it is very important in order to obtain a highest biogas yield [8].

One of the indicators used to control the stability of the process in the digester is $\mathrm{pH}$. The optimal $\mathrm{pH}$ range for mesophilic anaerobic digestion is close to neutrality, varying for each type of bacteria between 6.5 and $7.5[9]$.

The digester has shown no signs of instability during the experiment, since the environment was always maintained in favorable alkaline conditions for anaerobic digestion. The optimum $\mathrm{pH}$ value during the experiment is of the order of 7.1.

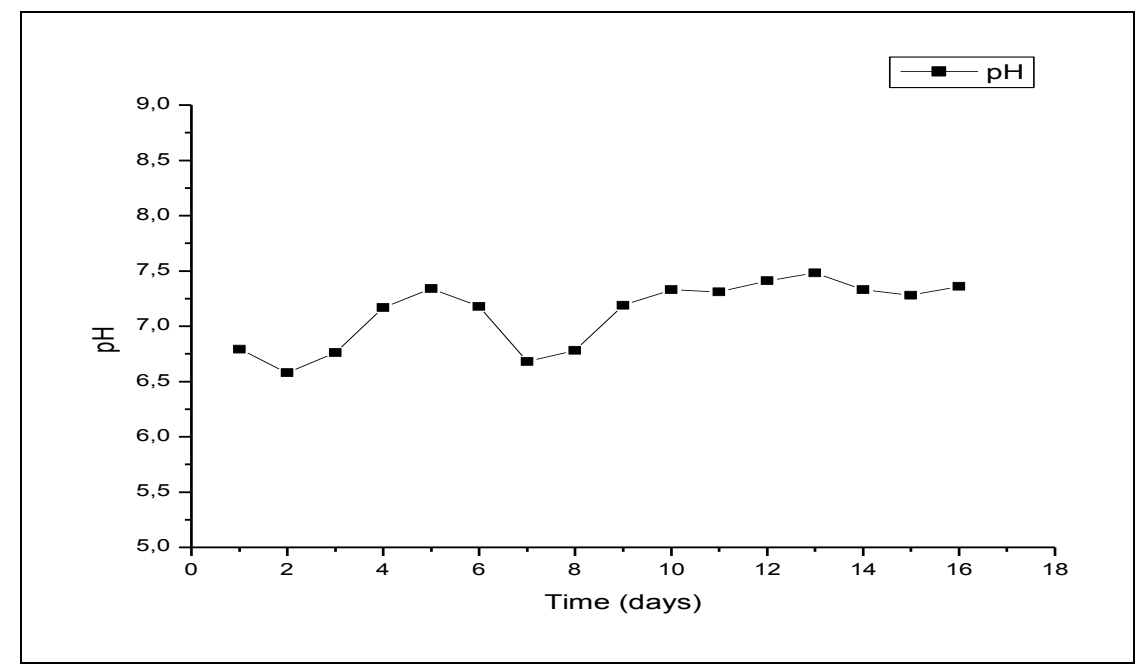

Figure (1). Change in $\mathrm{pH}$ during the anaerobic digestion of vinasse as a function of the residence time

Fig. (1) shows that the $\mathrm{pH}$ at inside the digester is controlled in the range limited all through the anaerobic digestion. This stability is important because the ecosystem and more specifically, the methanogenic microorganisms are very sensitive to variations in $\mathrm{pH}$, which can lead to the generation of AGV non-ionized forms, which inhibit the process. Consequently the stability of these conditions indicates that the conduct of the increasing load is well underway, which promotes the proper functioning of the anaerobic digestion order to ensure a remarkable biodegradability, and thus obtain a good production of biogas.

\section{III.2 Evaluation of organic matter:}

Another parameter that controls the anaerobic digestion is the evolution of organic matter throughout the experiment, expressed as volatile materials.

TALE 3. Physico-chemical parameters during the anaerobic digestion of vinasse

\begin{tabular}{lllll}
\hline & \multicolumn{2}{c}{ Load 0.25g SV } & \multicolumn{3}{c}{ Load 0.5g SV } \\
\cline { 2 - 5 } Parameters & Initial & Final & Initial & Final \\
\hline pH & 6.78 & 6.79 & 7.19 & 7.36 \\
TS (g/L) & 14.9 & 14.79 & 14.79 & 14.87 \\
MS (g/L) & 3.84 & 3.68 & 3.68 & 3.97 \\
VS (g/L) & 11.06 & 11.11 & 11.11 & 10.9 \\
\hline
\end{tabular}

TABLE 3 shows the results of the physico-chemical characteristics in the digester at the beginning and the end of each load.

The increase in the concentration of organic matter in the digester is due to the accumulation of nonbiodegradable substrate. The subsequent change in the behavior of the system is due to microbial adaptation of substrate consumption. The organic matter consisting of microorganisms, are used as a substrate, eliminating the organic matter existing in the form of volatile solids. 


\section{III.3 Estimated of biogas production:}

A fundamental part of this experiment is to determine the most favorable conditions for the optimal production of biogas from the anaerobic digestion of vinasse.

Theoretically, the Chen-Hashimoto model estimates by calculation a specific production of methane in $\mathrm{m}^{3}$ per $\mathrm{kg}$ of dry organic matter (OM) initially admitted in an anaerobic reactor [10].

In this model, the specific production (B) is expressed by the formula:

$B=B_{0} \times\left[1-\left(\frac{K}{\mu m-H R T}+K-1\right)\right]$

Where

Biological

$\mathrm{B}_{0}: \quad$ Theoretical Hence:

$$
K=0,6+0,021 \times 10^{0,05} \times[O M]
$$

$[\mathrm{OM}]$ : organic matter concentration $\left(\mathrm{g} / 1\right.$ or $\left.\mathrm{kg} / \mathrm{m}^{3}\right)$

$\mu_{\max }$ : kinetic coefficient.

$\mu_{\max }=0.013 \mathrm{~T}-0.129\left(\mathrm{~T}:\right.$ Fermentation temperature $\left.{ }^{\circ} \mathrm{C}\right)$

HRT: Hydraulic retention time (days).

The theoretical potential of biogas $(60 \% \mathrm{CH} 4) \mathrm{B}_{0}$, for the distillation residues is $0.7 \mathrm{~m}^{3} / \mathrm{kg}$ dry OM [10].

The theoretical biogas calculated from the model of Chen-Hashimoto at a controlled temperature of $35^{\circ} \mathrm{C}$, for a quantity of vinasse treated with dry organic matter (volatile solids) of $11.11 \mathrm{~g} / \mathrm{L}$ during the anaerobic digestion is $0.84 \mathrm{~m}^{3} / \mathrm{kg}$ of VS.

\section{III.4 Experimental Production of biogas:}

Considering the complexity of the estimated calculation including difficulties in determining the inhibition coefficient $\mathrm{K}$, the experimental test to find the methane potential can give a precise answer to the question of methane production for any substrate.

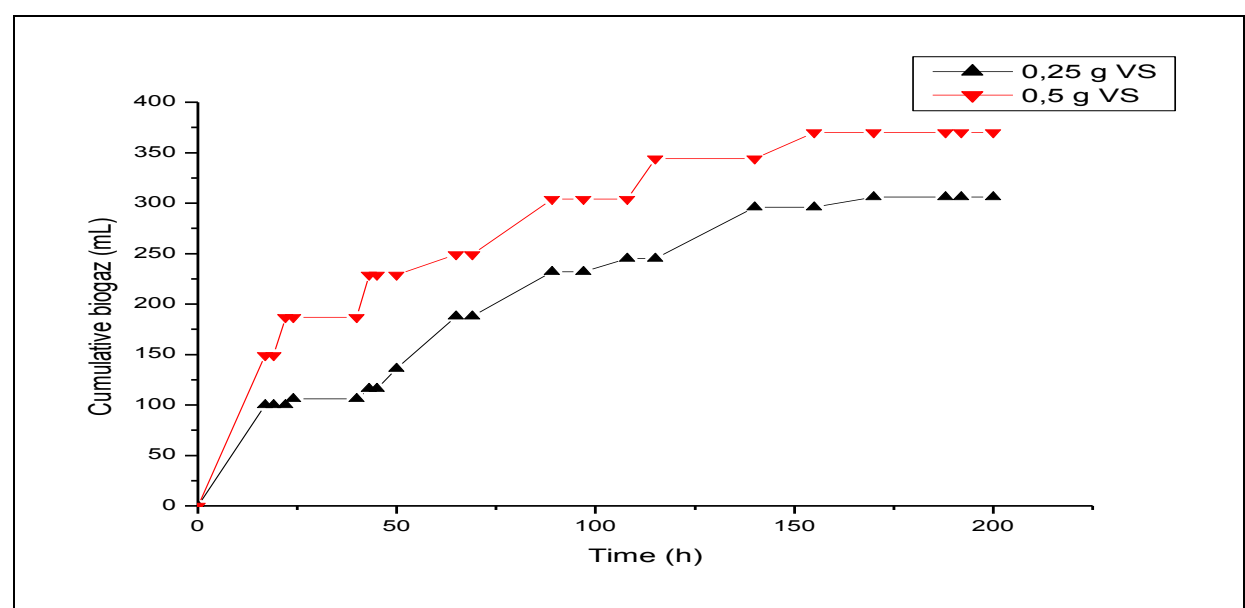

Figure (2). The biogas production during the anaerobic digestion of vinasse for different loads $(0.25 \mathrm{~g}$ and $0.5 \mathrm{~g}$ SV)

Fig. (2) shows that the volume of biogas production increases with the increase in load (from $0.25 \mathrm{~g}$ to $0.5 \mathrm{~g}$ VS added). This phenomenon is due to the degradation of the added available organic material that emerges in the form of biogas, with the maintenance of the stability of the control parameters of anaerobic digestion.

As previously mentioned, a larger quantity of volume of biogas was produced after the increase of the load and for a load of $0.25 \mathrm{~g} \mathrm{VS}$ added, the amount of accumulated biogas is $300 \mathrm{~mL}$, and a load of $0.5 \mathrm{~g}$ VS added, the amount of accumulated biogas is $370 \mathrm{ml}$. In addition, the slopes of the curves also decrease with time at the end 
of each load. This decrease in slope, accompanied by a reduction in the volume of biogas produced can be explained by the progressive reduction in the concentration of biodegradable substrate.

The coefficient of biogas yield can be determined from the maximum volume of biogas produced experimentally $\left(\mathrm{G}_{\mathrm{r}}\right)$ and the quantity of volatile solids added to the higher load $\left(\mathrm{Q}_{\mathrm{r}}\right)$. The coefficient of biogas yield is calculated using the following equation:

$$
Y=\frac{G_{r}}{Q_{r}}
$$

Where:

Y: the coefficient of biogas yield;

Gr: the accumulated volume of biogas after a load (L) volume;

Qr: the quantity of the higher load SV added (g / L);

$$
Y=\frac{0.37 L}{0.5 g V S}=0.74 L / g V S
$$

The coefficient of performance of biogas for the higher load added during the experience, which is $0.5 \mathrm{~g} \mathrm{SV}$ added, with a maximum volume of biogas production of $370 \mathrm{ml}$, is $0.74 \mathrm{~L} / \mathrm{g}$ VS.

TABLE 4 shows a comparison between the results of biogas produced from the anaerobic digestion of vinasse. In the literature, the anaerobic digestion of waste distillation shows interesting results to produce biogas; between 350 and $700 \mathrm{~m}^{3} / \mathrm{t}$ of dry organic matter (biogas to $60 \% \mathrm{CH}_{4}$ ) [10] or also $0.68 \mathrm{~m}^{3} / \mathrm{kg} \mathrm{SV} \mathrm{[12].}$

\begin{tabular}{|c|c|c|c|c|}
\hline & & \multicolumn{2}{|c|}{ DATA } & \multirow{2}{*}{$\begin{array}{l}\text { RESULTS } \\
\text { Biogas potential }\end{array}$} \\
\hline & & $\begin{array}{l}\text { TS } \\
(\mathrm{g} / \mathrm{L})\end{array}$ & $\begin{array}{l}\text { VS } \\
(\mathrm{g} / \mathrm{L})\end{array}$ & \\
\hline \multirow[t]{2}{*}{ Laboratory experience } & Experimental & \multirow[t]{2}{*}{43.47} & \multirow[t]{2}{*}{25.46} & $0.7\left(\mathrm{~m}^{3} / \mathrm{kg} \mathrm{VS}\right)$ \\
\hline & Calculated (Chen-Hashimoto) & & & $0.8\left(\mathrm{~m}^{3} / \mathrm{kg}\right.$ VS $)$ \\
\hline \multirow[t]{4}{*}{ Bibliography } & Moletta R. et al. (2008) [10] & N.A. & N.A. & 0.35 to $0.7\left(\mathrm{~m}^{3} / \mathrm{kg} \mathrm{VS}\right)$ \\
\hline & Sales D. et al. (1989) [13] & 23.00 & 12.80 & $0.36\left(\mathrm{~m}^{3} / \mathrm{kg} \mathrm{DVS}\right)$ \\
\hline & Meynell P.J. (1976) [12] & - & - & $0.68\left(\mathrm{~m}^{3} / \mathrm{kg} \mathrm{VS}\right)$ \\
\hline & Pound B. et al. (1981) [12] & N.A. & N.A. & 0.24 to $0.37\left(\mathrm{~m}^{3} / \mathrm{kg} \mathrm{TS}\right)$ \\
\hline
\end{tabular}

TABLE 4. Comparison between the results of biogas obtained from the experience and bibliography

N.A. : Not Available

One can deduce that theoretically the range of biogas production from anaerobic digestion of waste distillation of alcohol is between 0.35 and $0.7 \mathrm{~L} / \mathrm{g}$ dry organic matter (which represent the volatiles dry). While the results obtained in this experiment are similar and have not exceeded the range reported in the literature. This shows that the anaerobic digestion of this type of waste is a reliable solution for the production of biogas, which can be valued as a source of renewable energy, and that will allow the industry to save significant gains. Also, later experiments have also shown that anaerobic digestion of vinasse supplemented by other chemical treatments such as ozonation [8], gives even more remarkable results, and contributes to a significant removal of refractory compounds [14], seen that some effluents such as those derived from organic material having undergone thermal treatments have a "hard COD" important and result in low yields of methane, which is the case for the vinasses produced from molasses, where the purification efficiency remains low, at around $60 \%$. In this case, it is not the distillation of alcohol is the cause but only undergoes treatment molasses in the sugar [10].

One can then deduce that the anaerobic digestion is a very reliable solution for the treatment of vinasse to produce of biogas but to optimize the purification yield, given the chemical complexity of vinasse, it is necessary that such waste is pre-treated to minimize, or even eliminate the pollution load.

\section{CONCLUSION}

The experience of the mesophilic anaerobic digestion of vinasse, showed no signs of instability throughout the process, which lasted 16 days, with a $\mathrm{pH}$ of around 7.1, and allowed to have a coefficient of biogas yield is $0.7 \mathrm{~L} / \mathrm{g}$ VS.

On the basis of results of this experiment, we can deduce that the vinasse is a potential source for the production of biogas, and the process of anaerobic digestion presents a reliable solution for the treatment of this type of waste. But to ensure a more significant purification yield, the anaerobic digestion of vinasse must be preferably completed by another chemical pretreatment. 


\section{REFERENCES}

[1] Elvers, B., Hawkins, S., Weinheim, G. S.; (1990). "Ullmann's encyclopaedia of industrial chemistry", fifth ed, NY:VCH., Basel (Switzerland), Cambridge, New York.

[2] Borja R., Martin A., Luque M., Duran M.M., (1992). "Kinetic study of anaerobic digestion of wine distillery wastewater".

[3] Cortez L.A.B., Perez L.E.B. ; (1997). ''Experiences on vinasse disposal. Part III: Combustion of vinasse' - \# 6 Fuel Oil Emulsions, Brazilian Journal of Chemical Engineering, 14(1).

[4] Martin M.A., Raposo F., Borja F., Martin A.; (2001). "Kinetic study of the anaerobic digestion of vinasse pretreated with ozone, ozone plus ultraviolet light, and ozone plus ultraviolet light in the presence of titanium dioxide".

[5] D’Aquino C. A., Mello T. C., Costa L. C. J., Fedalto L., Leite C., Torrens J. C. L.; "The state-of-the-art of anaerobic treatment of sugarcane vinasse".

[6] Samuel N. M. de Souza, Reginaldo F. Santos, Guilherme P.M. Fracaro ; (2011). "Potential for the production of biogas in alcohol and sugar cane plants for use in urban buses in the Brazil". Bioenergy Technology (BE).

[7] APHA (American Public Health Association); (1989). "Standard Methods for the Examination of Water and Wastewater", 17 ${ }^{\text {th }}$ ed. Washington, DC, USA.

[8] Siles J.A., El Bari H., Ibn Ahmed S., Chica A. F., Martín M.A.; (2010). "Pretreatment : The key issue in vinasse valorization. Preprocessing of manure and organic waste for energy production".

[9] Martí, N.; (2006). "Phosphorus precipitation in anaerobic digestion process". Dissertation.com. Boca Raton, Florida.

[10] Moletta R. ; (2008). 'La méthanisation', ; Editions Tec et Doc, Publication Lavoisier.

[11] Coudure R., Castaing J.; (1997). 'Bilan de fonctionnement d'une unité de méthanisation de lisier de porc'. Journées Rech. Porcine en France, 29, 335-342.

[12] Pound B., Done F., Preston T.R.; (1981). 'Biogaz production from mixtures of cattle slurry and pressed sugar cane stalk, with and without urea', Trop Anim Prod 1981 6:1.

[13] Sales D., Valcarcel M. J., Romero L. I. \& Martinez de la Ossa E.; (1988). “'Anaerobic Digestion Kinetics of Wine-Distilleries Wastewaters', Clieni. Tech. Biofcdinol. 1989, 45, 147- 162.

[14] Robles-Gonzalez V., Galindez-Mayer J., Rinderknecht-Seijas N., Poggi-Varaldo H.M.; (2011). '’Treatment of mezcal vinasses: A review. Journal of Biotechnology 157 (2012) 524-546. 